\title{
AKILLI FABRİKALARDAKİ OTONOM TAŞIYICILAR İÇİN BULANIK MANTIK TABANLI ANOMALİ TESPITI
}

\author{
Özlem ÖRNEK ${ }^{1 *}$, Eyyüp GÜLBANDILAR², Ahmet YAZICI ${ }^{3}$
}
${ }^{1}$ Eskişehir Osmangazi Üniversitesi, Mühendislik Mimarlık Fakültesi, Batı Meşelik Yerleşkesi, Bilgisayar Mühendisliği Bölümü, Eskişehir, ORCID No: http://orcid.org/0000-0002-8775-8695
${ }^{2}$ Eskișehir Osmangazi Üniversitesi, Mühendislik Mimarlık Fakültesi, Batı Meșelik Yerleșkesi, Bilgisayar Mühendisliği Bölümü, Eskișehir, ORCID No: http://orcid.org/0000-0001-5559-5281
${ }^{3}$ Eskişehir Osmangazi Üniversitesi, Mühendislik Mimarlık Fakültesi, Batı Meșelik Yerleșkesi, Bilgisayar Mühendisliği Bölümü, Eskişehir, ORCID No: http://orcid.org/0000-0001-5589-2032

\begin{tabular}{|c|c|}
\hline Anahtar Kelimeler & Öz \\
\hline Anomali Tespiti & Dijital dönüşüm, sanayideki birçok sürecin veri odaklı yeni yaklaşımlarla ele alınmasını \\
\hline Bulanık Mantık & gerekli kılmaktadır. Bu bağlamda Endüstri 4.0 ile beraber akıllı fabrikalarda önemli \\
\hline Akıllı Fabrika & dijital dönüșüm çalışmaları gerçekleșmektedir. Akıllı fabrikalardaki dijital dönüșüme \\
\hline Otonom Araç & katkı sağlayacak en önemli teknolojilerden bir tanesi de otonom taşıyıcı araç \\
\hline & $\begin{array}{l}\text { (OTA)'lardır. OTA'ların fabrika içerisindeki görevlerini verimli bir şekilde } \\
\text { gerceklestirmeleri ve beklenmedik bir problem veva aksama olduăunda insan }\end{array}$ \\
\hline & müdahalesi olmadan bu durumun veri üzerinden tespiti önemlidir. Bu çalışmada, \\
\hline & OTA'ların fabrika içerisindeki trafik ağında oluşabilecek beklenmedik; durma, \\
\hline & $\begin{array}{l}\text { yavașlama vb. kaynaklı anormal durumların tespıtı ıçın Bulanık mantık tabanlı anomalı } \\
\text { tespiti önerilmektedir. Yapılan testlerde önerilen yöntemin } \% 71,87 \text { başarıyla sonuç } \\
\text { vermektedir. }\end{array}$ \\
\hline
\end{tabular}

\section{FUZZY LOGIC BASED ANOMALY DETECTION FOR AUTONOMOUS TRANSPORT VEHICLES IN SMART FACTORIES}

\begin{tabular}{|c|c|}
\hline Keywords & Abstract \\
\hline $\begin{array}{l}\text { Anomaly Detection } \\
\text { Fuzzy Logic } \\
\text { Smart Factories } \\
\text { Autonomous Vehicle }\end{array}$ & $\begin{array}{l}\text { Digital transformation requires new data-oriented approaches in industry. In this } \\
\text { context, there are significant studies for digital transformation of the smart factories } \\
\text { with Industry 4.0. Autonomous transport vehicle (ATV) is one of the most important } \\
\text { technologies for digital transformation in smart factories. ATVs are expected to perform } \\
\text { their tasks in the factory in an efficient manner. And it is also expected to detect an } \\
\text { unexpected problem or any failure via the data without human intervention. This study } \\
\text { aimed determining abnormal conditions of traffic network such as unexpected stop and } \\
\text { deceleration by using fuzzy logic in the factory. The performed tests show that the } \\
\text { proposed method results success (71.87\%). }\end{array}$ \\
\hline Araștırma Makalesi & Research Article \\
\hline Başvuru Tarihi & Submission Date \\
\hline Kabul Tarihi & Accepted Date \\
\hline
\end{tabular}

\section{Giriş}

Dijitalleşme ile birçok alanda veri odaklı dönüşümler olmaktadır. Endüstri 4.0 ile beraber akıllı fabrikalarda önemli dijital dönüşümlerin olması beklenmektedir. Akıllı fabrikalarda dijital dönüşümü sağlayacak kritik teknolojilerden biri otonom taşıyıcı araç (OTA)'lardır. OTA'lar, fabrika içi lojistikte malzemelerin taşınması vb. görevleri yerine getirmektedir. $\mathrm{Bu}$ taşıma görevleri sırasında fabrika içi taşımacılıkta oluşabilecek durma, yavaşlama vb. istenmeyen ya da olağan dışı durumların veri odaklı tespiti önemlidir (Tao, Qi, Liu, and Kusiak, 2018).
Literatüre bakıldığında fabrika içi sistemler için veri odaklı anomali tespitine yönelik yaygın çalışmalara rastlanmamış olup bazı öncül çalışmalar yapılmıștır (Örnek, Vatan, Sarıoğlu ve Yazıcı, 2018). Ancak, normal trafik ağlarında veri odaklı bazı anomali tespitine yönelik çalışmalara rastlanmıştır (Li, Guo, Xia ve Xie, 2018; Thaika, Tasneeyapant ve Cheamanunkul, 2018). Yujun, Juhua, Jiahong, Yue ve Zhang (2019), Poisson karışımı modeli (Poisson mixture model) (PMM) ve birleşik gizli Markov modelini (coupled hidden Markov model) (CHMM) taksi küresel konumlandırma sistemi verilerinden gelen trafik anormalliklerini tespit etmek

\footnotetext{
*Sorumlu yazar; e-posta : ozlemmornek@gmail.com
} 
için kullanmışlardır. Pu, Wang, Liu and Zhang (2019), STLP-OD (spatial and temporal label propagation outlier detection) (mekansal ve zamansal etiket yayılımı aykırı değer tespiti) çerçevesi önererek, trafik anomalilerinin bir yoldan diğer komşu yollara uzamsal ve zamansal yayılımını göz önünde bulundurmuşlardır. STLP-OD çerçevesinin değerlendirilmesini 12.266 taksinin yörünge verisi ile yapmışlardır. Li ve diğ. (2018), trafik video görüntülerinden elde edilen araç yörünge, araç ve piksel istatistik bilgilerini bulanık hareket, trafik akıșı (traffic flow) ve trafik yoğunluğunu (traffic density) kullanarak anomali tespitini yapmışlardır. Thaika ve diğ. (2018), hedef bölge için belirli zaman aralıklarında GPS verilerinden özellikler çıkarmış, Temel Bileşen Analizi (PCA) kullanarak tespit modelini eğitmiştir. Daha sonra modeli kullanarak anomali tespiti yapmışlardır. Bu alanda bulanık mantık tabanlı anomali tespiti için de farklı çalışmalar bulunmaktadır. Rossi, Gastaldi, Gecchele ve Barbaro (2015), yoğunluk, ortalama hız ve akıș oranı verileri ile bulanık mantık tabanlı olay tespiti yapmışlardır. Nikolaev ve Sapego (2016), akış oranı, oran değişimi, akış hacmi ve hacim değişim verileri ile bulanık mantık tabanlı olay statüsünü; trafik normal, olay muhtemelen meydana geldi veya olay bulundu olarak tespit etmişlerdir. Nikolaev, Sapego, Jakubovich, Berner ve Stroganov (2016), akış oranı (flow rate), hız değişimi, hacim akışı (volume flow) ve hacim değişikliği verileri ile önceliği tanımlamak için bulanık mantığa dayalı bir algoritma önermişlerdir. Rossi, Gastaldi ve Gecchele (2018), otoyol rampa birleşme bölgelerinden gelen araç döngü detektörü verilerinden olayları tanımlayabilen bir kontrol sistemi sunmuşlardır. Sistem bulanık mantık kavramları ile geliștirilmiş ve mikro-simülasyon deneylerinden elde edilen verilerle test edilmiștir. El Hatri ve Boumhidi (2018), şerit üzerinde seyahat eden araçların ortalama hızını, şerit doluluk oranını, mevcut trafik akışını ve önceki zaman aralıklarındaki akış hızını içeren trafik bilgileri ile trafik akışının mekansal ve zamansal korelasyonlarını ele alan bir bulanık derin öğrenme temelli trafik olay tespit yöntemi önermiştir.

Yukarıda verilen literatürde normal trafik ağları için anomali tespitine yönelik çalışmalar olmakla beraber bunların fabrika içi trafik ağlarına direk uygulanabilme imkanı yoktur. Fabrika içi trafik ağları normal trafik ağlarıyla yapısal bazı benzerlikler taşımakla beraber işlevsel olarak farklı karakteristikler göstermektedir. Örneğin fabrika içi trafik ağlarında belli noktalar, kısa mesafeler arası eşya taşımacılığı trafiğin temel karakteristiğini oluşturmaktadır. Dolayısıyla fabrika içerisindeki yükleme, boşaltma veya yaya yoğunluğundan kaynaklı anomalilerin tespiti önemlidir. Akıllı fabrikalarda OTA'ların olușturduğu trafik ağı için anomali tespiti oldukça yenidir. Diğer taraftan bu alanda bulanık mantık tabanlı bir çalışmaya rastlanılmamıştır.

Bu çalışmada zaman, ortalama hız, yaya yoğunluğu ve işlem süresi verileri kullanılarak akıllı fabrikalardaki
OTA'lar için bulanık mantık tabanlı anomali tespit yöntemi önerilmektedir. Normal trafik ağları anomali tespit çalışmalarından farklı olarak fabrika içi trafikte anomaliye neden olan yaya yoğunluğu, yük doldurma boşaltma gibi olaylar bu çalışmada dikkate alınmaktadır. Takip eden bölüm 2'de anomali tespiti ve bulanık mantık ile ilgili genel bilgiler verilmektedir. Bölüm 3, anomali tespiti için önerilen yöntem ile ilgilidir. Bölüm 4'te veri kümesi ve önerilen anomali tespit yönteminin uygulanması ve sonuçları verilmektedir.

\section{Anomali Tespiti ve Bulanık Mantık ile İlgili Mevcut Literatür Çalışmaları}

Anormal olaylar sistemlerin yanlış bir şekilde çalışmasına veya beklenen verimliliği sergileyememesine neden olabilir. Bu nedenle anormal olayların, sistemi etkileyerek kötü sonuçlara sebep olmasını önlemek ve erken müdahale etmek için tespit edilmesi önemlidir. Takip eden alt bölümde literatürde anormal olayların tespiti için kullanılan farklı yöntemler ve bulanık mantık temelleri verilmektedir.

\subsection{Anomali Tespiti}

Anomali tespiti ile sistemlerde oluşan anormal olayların veri odaklı tespiti hedeflenmektedir. Anomali tespit yöntemleri anomaliyi oluşturan veri tiplerine göre değişiklik göstermektedir. $\mathrm{Bu}$ anomali tipleri; nokta, bağlamsal ve toplu olmak üzere üçe ayrılmaktadır. Nokta anomalide, bireysel veri örneği geri kalan verilere göre, bağlamsal anomalide (koşullu anomali) bir veri örneği belirli bir bağlama göre, toplu anomalide ise tüm veri kümesine göre veri örneklerinin koleksiyon olarak bir araya gelmelerine göre anormallik değerlendirilmesi yapılır (Chandola, Banerjee ve Kumar, 2007).

Anomali tespiti için kullanılan yöntemler anomali tipine göre belirlenir. Nokta anomalisi tespitinde sinıflandırma tabanlı teknikler, en yakın komşu bazlı teknikler, kümeleme tabanlı teknikler ve istatistik tabanlı vb. teknikler kullanılmıştır.

Sinıflandırma tabanlı anomali tespitinde Sinir ağ temelli yaklaşımlar, Destek Vektör Makineleri (SVM), Bayes ağları temelli yaklaşımlardır. Kural tabanlı teknikler ise Bulanık mantık ve Genetik algoritmalar gibi yöntemlerdir. Tablo 1'de literatürde sınıflandırma tabanlı anomali tespitinde kullanılan bazı yöntemler verilmiștir. Takip eden alt bölümde bu çalışmada kullanılan bulanık mantık yöntemi ile ilgili temel bilgiler verilmektedir. 
ESOGÜ Müh Mim Fak Derg. 2020, 28(1), 53-61

Tablo 1

Sınıflandırma Tabanlı Algoritmalar ile Trafik Ağlarında Anomali Tespiti

\begin{tabular}{lc}
\hline Çalışma & $\begin{array}{c}\text { Sinıflandırma } \\
\text { Tabanlı Algoritma }\end{array}$ \\
\hline $\begin{array}{l}\text { La-inchua, Chivapreecha ve } \\
\text { Thajchayapong (2013) }\end{array}$ & Bulanık Mantık \\
Liu, Lu, Chen ve Zhao (2014) & $\begin{array}{c}\text { Bayes Ağları Tabanlı } \\
\text { (Naive Bayes) }\end{array}$ \\
Dardor, Chlyah ve Boumhidi (2018) & $\begin{array}{c}\text { Genetik Algoritma ve } \\
\text { SVM }\end{array}$ \\
Dogru ve Subasi (2018) & $\begin{array}{c}\text { Kural Tabanlı Teknik } \\
\text { (Random Forest) }\end{array}$ \\
Ki, Heo, Choi, Ahn ve Park (2018) & $\begin{array}{c}\text { Sinir Ağı Tabanlı } \\
\text { (Yapay Sinir Ağları) }\end{array}$ \\
\hline
\end{tabular}

\subsection{Bulanık Mantık}

Bulanık mantık, insan düșünme ve karar verme yeteneklerine benzer şekilde sözel ifadeleri dikkate alan akıllı bir çözüm yaklaşımıdır. Bu çözümlerde genellikle Mamdani yaklaşımı tercih edilmektedir (Mamdani ve Assilian, 1975). Bu yöntem farklı problemlerin çözümünde genel olarak aşağıda verilen dört süreçten oluşmaktadır:

1. Bulanıklaştırma (Fuzzification): Giriş değerlerinin bulanık küme üyelik derece değerleri, belirlenen üyelik fonksiyonları ile belirlenir. Bu değerlere bulanık giriş değerleri de denir.

2. Kurallar (Rules): Çıkış bulanık küme değerleri (bulanık çıkış değerleri) ile giriş kümeleri arasındaki ilişkinin belirlenmesi için kurallar oluşturulur.

3. Çıkarım (Inference): Çıkış değerleri için belirlenen bulanık küme değerlerinin (bulanık çıkış değerleri), bulanık giriș değerlerini kurallar ile kullanıldıktan sonra Max-dot vb. yöntemler kullanılması ile belirlenmesidir.

4. Berraklaştırma (Defuzzfication): Bulanık değerlerin ham değerlere dönüştürülmesi işlemidir. Sonuç çıkarımı sonucunda elde edilen bulanık çıkış değerleri ağırlık merkezi vb. yöntemler ile kullanılarak berraklaştırma işlemi gerçekleştirilir, çıkış verisi ham değerleri elde edilir.

Bulanık sistemin girișine sağlanan veriler kesin giriș verileri olarak adlandırılır. Bu veriler kontrol sürecinin gerçek değişkenleri olarak tanımlanır. Bulanık mantık sisteminin çıkışında üretilen veriler ise, çıkış değişkenine karşılık gelir ve kesin çıkış verileri olarak adlandırılır. Bulanık mantığa dayalı sistem aşağıdaki unsurlardan oluşur (Zadeh, 1988):

- Kesin giriş verileri,

- Dilsel değişkenler ve terimler,

- Bulanık kurallar,

- Üyelik fonksiyonları,

- Kesin çıtı verileri.
J ESOGU Engin Arch Fac. 2020, 28(1), 53-61

Bulanık mantık sistemi, giriş verileri ve bir çıkışa sahip koșullu kurallar «EĞER-ISE » ile tanımlanmaktadır. Kuralın ilk bölümü ("ISE" den önce), uzman bilgisi ile oluşturulmuş dilsel değișkenler «ve» ve «değil» gibi mantıksal operatörler kullanılarak tanımlanır. İkinci bölüm ("İSE" den sonra) sonuç olarak adlandırılır (Zadeh, 1988).

Takip eden alt bölümde önerilen bulanık mantık tabanlı anomali tespit yöntemi verilmektedir.

\section{3. Önerilen Yöntem}

Fabrika içi lojistikte farklı nedenlerden dolayı OTA’ların çalışmaları sırasında anomaliler meydana gelebilmektedir. Eğer bu anomaliler zamanında tespit edilmezse fabrika içi süreçlerde aksamalar oluşabilir. Verimliliğin sağlanması, durumun kontrol altına alınması ve kötüye gitmesini engellemek için veri üzerinden anomali tespiti yapılması önemlidir. $\mathrm{Bu}$ nedenle akıllı fabrika içerisinde lojistik görevlerini yerine getiren OTA'lar için bulanık mantık tabanlı anomali tespiti yöntemi önerilmektedir.

Akıllı fabrika trafik ağında yer alan OTA'lar, lojistik görevleri yerine getirmeleri sırasında anomaliler oluşabilmektedir. Anomalilere örnek olarak beklenmeyen yaya yoğunluğu, araç sorunları veya doldurma boşaltma noktalarında meydana gelebilecek aksamalar verilebilir. Oluşabilecek bu anormal durumların tespiti için Bulanık Mantık tabanlı anomali tespiti yöntemi kullanılmıştır. Bulanık Mantık tabanlı anomali tespiti, bulanık mantık süreçlerinde kullanılacak kesin giriş verileri, dilsel değişkenler, bulanık kurallar, üyelik fonksiyonları ve kesin çıktı verileri belirlenmiştir:

- Kesin giriş verileri: Zaman, ortalama hız, işlem süresi ve yaya yoğunluğudur.

- Kesin çıkış verileri: Anomali durumu ("var" veya "yok") ve anomali oranıdır.

- Giriş verileri dilsel değişkenler: Zaman için T1, T2 ve T3, ortalama hız için V1, V2 ve V3, işlem süresi için PT1, PT2 ve PT3, yaya yoğunluğu için $\mathrm{P} 1, \mathrm{P} 2$ ve $\mathrm{P} 3$ şeklindedir.

- Çıkış verisi dilsel değişkenler: Anomali durumu; "var", "yok" ve anomali oranı için R1, R2 ve R3'tür.

- Bulanık kurallar: Aşağıda oluşturulan bulanık kurallardan örnekler verilmektedir. 


$\begin{array}{lllllllll}\text { Eğer } & \text { T1 } & \text { ve } & \text { V1 } & \text { ve } & \text { P1 } & \text { ve } & \text { PT1 ise R2 } \\ \text { Eğer } & \text { T1 } & \text { ve } & \text { V1 } & \text { ve } & \text { P1 } & \text { ve } & \text { PT2 ise R3 } \\ \text { Eğer } & \text { T1 } & \text { ve } & \text { V1 } & \text { ve } & \text { P1 } & \text { ve } & \text { PT3 ise R1 } \\ \text { Eğer } & \text { T1 } & \text { ve } & \text { V1 } & \text { ve } & \text { P2 } & \text { ve } & \text { PT1 ise R2 } \\ \text { Eğer } & \text { T1 } & \text { ve } & \text { V1 } & \text { ve } & \text { P2 } & \text { ve } & \text { PT2 ise R1 } \\ \text { Eğer } & \text { T2 } & \text { ve } & \text { V1 } & \text { ve } & \text { P1 } & \text { ve } & \text { PT1 ise R2 } \\ \text { Eğer } & \text { T2 } & \text { ve } & \text { V1 } & \text { ve } & \text { P1 } & \text { ve } & \text { PT2 ise R2 } \\ \text { Eğer } & \text { T2 } & \text { ve } & \text { V1 } & \text { ve } & \text { P1 } & \text { ve } & \text { PT3 ise R3 } \\ \text { Eğer } & \text { T2 } & \text { ve } & \text { V1 } & \text { ve } & \text { P2 } & \text { ve } & \text { PT1 ise R3 } \\ \text { Eğer } & \text { T2 } & \text { ve } & \text { V1 } & \text { ve } & \text { P2 } & \text { ve } & \text { PT2 ise R2 } \\ \text { Eğer } & \text { T3 } & \text { ve } & \text { V1 } & \text { ve } & \text { P1 } & \text { ve } & \text { PT1 ise R2 } \\ \text { Eğer } & \text { T3 } & \text { ve } & \text { V1 } & \text { ve } & \text { P1 } & \text { ve } & \text { PT2 ise R1 } \\ \text { Eğer } & \text { T3 } & \text { ve } & \text { V1 } & \text { ve } & \text { P1 } & \text { ve } & \text { PT3 ise R2 } \\ \text { Eğer } & \text { T3 } & \text { ve } & \text { V1 } & \text { ve } & \text { P2 } & \text { ve } & \text { PT1 ise R2 } \\ \text { Eğer } & \text { T3 } & \text { ve } & \text { V1 } & \text { ve } & \text { P2 } & \text { ve } & \text { PT2 ise R1 }\end{array}$

- Üyelik fonksiyonları: Şekil 1'de girişler ve çıkış için oluşturulan üyelik fonksiyonları verilmektedir.

Bulanık kurallar ve üyelik fonksiyonlarının dağılımı, deneysel çalışmalar sonucunda akıllı fabrika trafik ağında mantıksal olarak beklenen değer aralıkları ve konu ile ilgili bilgiye sahip kişilerden sağlanan bilgilerden baz alınarak olușturulmuştur.
Giriş Değerleri Üyelik Fonksiyonları
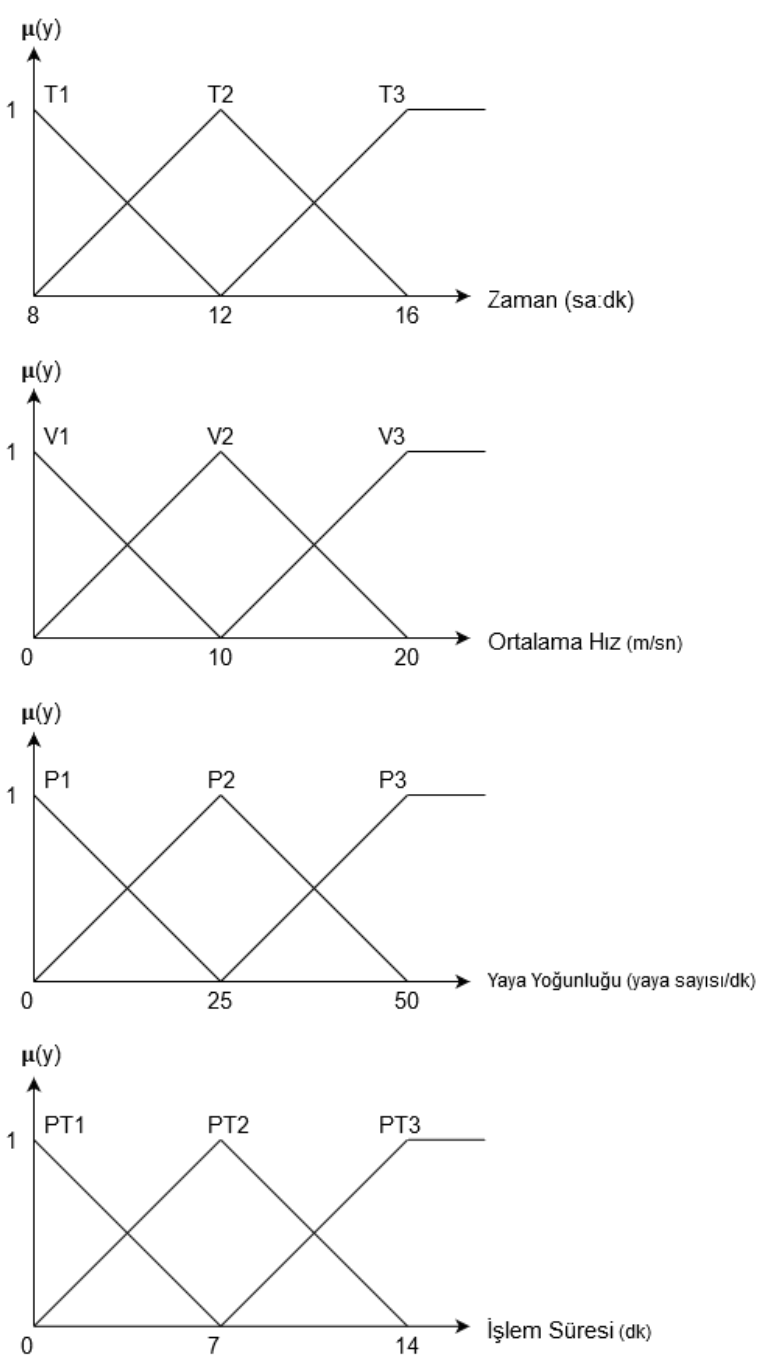

Çıkış Değeri Üyelik Fonksiyonu

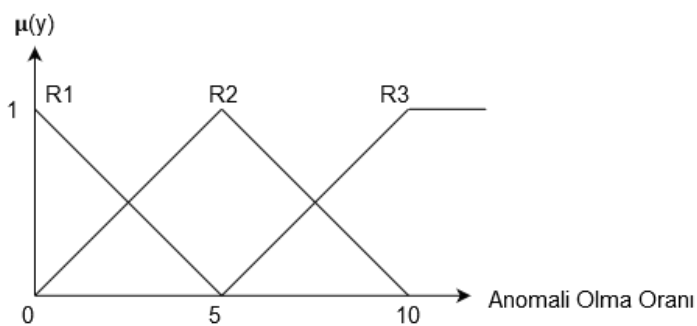

Şekil 1. Giriș Değerleri ve Çıkıș Değeri Üyelik Fonksiyonları

Bu çalıșmada bulanıklaștırma, kural değerlendirilmesi, kural çıktılarının toplanması ve berraklaştırma aşamaları uygulanmıştır. Bulanıklaştırma aşamasında kesin giriş verileri üyelik fonksiyonlarında kullanılmıştır. Bunun sonucunda her bir giriş verisinin, belirlenen dilsel değișkenler için üyelik dereceleri belirlenmiştir. Bu girdilere bulanıklaștırılmış girdiler de denilebilir. Kural değerlendirmesi aşamasında, bulanıklaştırılmış giriş verileri belirlenen kurallar ile kullanılarak kuralda belirlenen dilsel çıkış verileri elde 
edilmiştir. Kural çıktılarının toplanması aşamasında, Max-dot yöntemi ile tüm kural çıktıları ve bulanıklaştırılmış çıkış verileri birleştirilir (Mendel, 1995). Berraklaştırma aşamasında ise bulanıklaştırılmış çıkış verileri ağırlık merkezi yönteminde kullanılarak tek bir değer elde edilir (Mendel, 1995). Bu değer bize anomali oranını vermektedir. Tespit edilen anomali oranı ve verilerin anomali durumu ("var" veya "yok") ROC analizinde kullanılır. ROC analizinden anomali tespiti için uygun eşik değeri belirlenir. Belirlenen bu değer kullanılarak anomali tespiti yapılır. Aşağıda anomali tespiti sözde kodu verilmektedir.

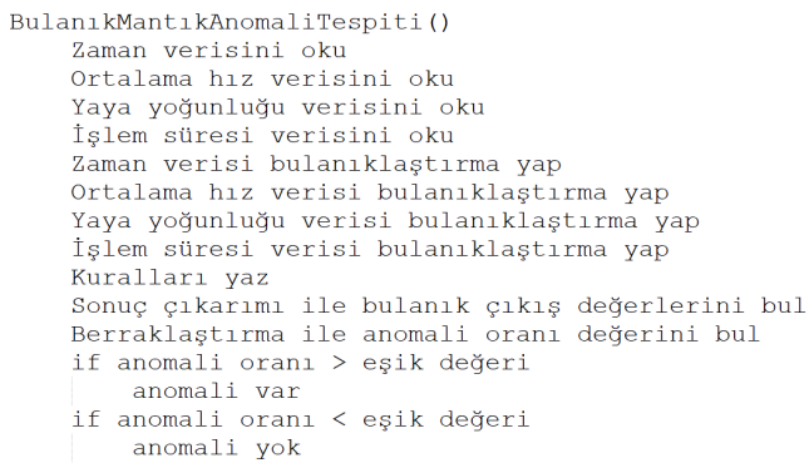

Bu çalışmada araştırma ve yayın etiğine uyulmuştur.

\section{Deneysel Çalışma}

Bu çalıșmada Örnek ve diğ., (2018) çalıșmasında kullanılan veri kümesi kullanılmıştır. Veri kümesindeki zaman, ortalama hız, işlem süresi ve yaya yoğunluğu verileri giriş değişkeni olarak kullanılmıştır. Giriş değişkenlerinin ham değerlerinin üyelik fonksiyonları Şekil 1'de tanımlanmıştır. Anomali "var" veya "yok" olarak etiketlenmiş yol aktif ve doldurma-boşaltma aktif veya pasif zamanlarına ait 2005 adet veri kullanılmıștır. Şekil 2'de veri kümesinin temel aldığı GAZEBO ortamında oluşturulmuş akıllı fabrika sanal ortamına ait görsel verilmektedir.

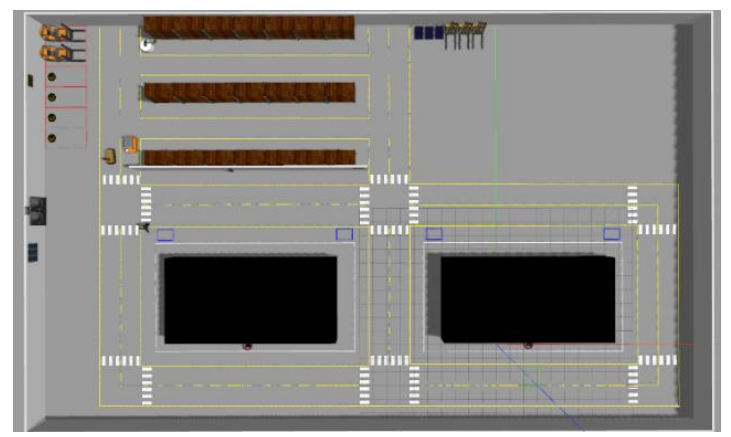

Şekil 2. GAZEBO Akıllı Fabrika Sanal Ortamı
GAZEBO akıllı fabrika sanal ortamı; malzeme doldurma boşaltma yerleri, raflar, yaya geçitleri ve yollardan oluşmaktadır. Veri kümesi, bu sanal ortama ait yaya geçidi veya doldurma-boşaltma yeri içeren iki yola ait verilerden oluşmaktadır. Veri kümesi kullanılarak Bulanık Mantık tabanlı anomali tespitinin gerçekleştirilmesi için "Python" programlama dili kullanılarak uygulama geliştirilmiştir. Veri kümesinin işlenmesi, Bulanık Mantık aşamaları ve deneyler bu uygulama ile gerçekleştirilmiştir.

İlk olarak giriş verilerinin paralel kenar ve üçgen üyelik fonksiyonlarına göre bulanıklaştırılması için gerekli formüller yazılmıștır. Zaman, ortalama hız, yaya yoğunluğu ve işlem süresi giriş verileri için üyelik fonksiyonları genel olarak aşağıdaki ifade ile analitik olarak tanımlanabilir (Nikolaev ve diğ., 2016):

$\mathrm{f}(\mathrm{x}, \mathrm{a}, \mathrm{b}, \mathrm{c}, \mathrm{d})=\left\{\begin{array}{c}0, \mathrm{x} \leq \mathrm{a} \\ \frac{x-a}{b-a}, \mathrm{a} \leq \mathrm{x} \leq \mathrm{b} \\ \frac{d-x}{d-c}, \mathrm{c} \leq \mathrm{x} \leq \mathrm{d} \\ 0, \mathrm{~d} \leq \mathrm{x}\end{array}\right.$

İkinci aşama olarak dilsel değişkenler için üyelik fonksiyonlarının tanımlaması yapılmıştır. Tanımlamalar aşağıda verilmektedir.

T1 değeri: $\mu \mathrm{TI}(\mathrm{T})=\left\{\begin{array}{c}1, T<8 \\ \frac{12-\mathrm{T}}{4}, 8 \leq \mathrm{T}<12 \\ 0,12 \leq \mathrm{T}<16 \\ 0, \mathrm{~T} \leq 16\end{array}\right.$

T2 değeri: $\mu \mathrm{T} 2(T)=\left\{\begin{array}{c}0, T<8 \\ \frac{T-8}{4}, 8 \leq T<12 \\ \frac{16-T}{4}, 12 \leq T<16 \\ 0, T \leq 16\end{array}\right.$

T3 değeri: $\mu \mathrm{T} 3(\mathrm{~T})=\left\{\begin{aligned} & 0, \mathrm{~T}<8 \\ & 0,8 \leq \mathrm{T}<12 \\ & \frac{\mathrm{T}-12}{4}, 12 \leq \mathrm{T}<16 \\ & 1, \mathrm{~T} \leq 16\end{aligned}\right.$

V1 değeri: $\mu \mathrm{w}(\mathrm{V})=\left\{\begin{array}{c}1, \mathrm{~V}<0 \\ \frac{10-\mathrm{V}}{10}, 0 \leq \mathrm{V}<10 \\ 0,10 \leq \mathrm{V}<20 \\ 0, \mathrm{~V} \leq 20\end{array}\right.$

V2 değeri: $\mu \mathrm{V} 2(\mathrm{~V})=\left\{\begin{array}{c}0, \mathrm{~V}<0 \\ \frac{\mathrm{V}}{10}, 0 \leq \mathrm{V}<10 \\ \frac{20-\mathrm{V}}{10}, 10 \leq \mathrm{V}<20 \\ 0, \mathrm{~V} \leq 20\end{array}\right.$ 
V3 değeri: $\mu \mathrm{vv}(T)=\left\{\begin{array}{c}0, \mathrm{~V}<0 \\ 0,0 \leq \mathrm{V}<10 \\ \frac{\mathrm{V}-10}{10}, 10 \leq \mathrm{V}<20 \\ 1, \mathrm{~V} \leq 20\end{array}\right.$

P1 değeri: $\mu \mathrm{PI}(\mathrm{P})=\left\{\begin{array}{c}1, \mathrm{P}<0 \\ \frac{25-\mathrm{P}}{25}, 0 \leq \mathrm{P}<25 \\ 0,25 \leq \mathrm{P}<50 \\ 0, \mathrm{P} \leq 50\end{array}\right.$

P2 değeri: $\mu \mathrm{P2}(\mathrm{P})=\left\{\begin{array}{c}0, \mathrm{P}<0 \\ \frac{\mathrm{P}}{25}, 0 \leq \mathrm{P}<25 \\ \frac{50-\mathrm{P}}{25,}, 25 \leq \mathrm{P}<50 \\ 0, \mathrm{P} \leq 50\end{array}\right.$

P3 değeri: $\mu \mathrm{Ps}(\mathrm{P})=\left\{\begin{array}{c}0, \mathrm{P}<0 \\ 0,0 \leq \mathrm{P}<25 \\ \frac{\mathrm{P}-2.5}{25}, 25 \leq \mathrm{P}<50 \\ 1, \mathrm{P} \leq 50\end{array}\right.$

PT1 değeri: $\mu \mathrm{PTI}(\mathrm{PT})=\left\{\begin{array}{c}1, \mathrm{PT}<0 \\ \frac{7-\mathrm{PT}}{7}, 0 \leq \mathrm{PT}<7 \\ 0,7 \leq \mathrm{PT}<14 \\ 0, \mathrm{PT} \leq 14\end{array}\right.$

PT2 değeri: $\mu \mathrm{PT2}(\mathrm{PT})=\left\{\begin{array}{c}0, \mathrm{PT}<0 \\ \frac{\mathrm{PT}}{7}, 0 \leq \mathrm{PT}<7 \\ \frac{14-\mathrm{PT}}{7}, 7 \leq \mathrm{PT}<14 \\ 0, \mathrm{PT} \leq 14\end{array}\right.$

PT3 değeri: $\mu \mathrm{PT} 3(\mathrm{PT})=\left\{\begin{array}{c}0, \mathrm{PT}<0 \\ 0,0 \leq \mathrm{PT}<7 \\ \frac{\mathrm{PT}-7}{7}, 7 \leq \mathrm{PT}<14 \\ 1, \mathrm{PT} \leq 14\end{array}\right.$

Üçüncü aşama olarak oluşturulan kural tabloları Maxdot yöntemi ile kullanılarak bulanık çıkış değerleri elde edilmiştir. Dördüncü aşamada bulanık çıkış değerleri ağırlık merkezi yöntemi ile berraklaştırılır ve sonuç olarak anomali olma oranı elde edilir. Tüm giriş değerleri için bu aşamalar gerçekleștirilmiştir. Elde edilen anomali olma oranı ve verilere ait anomali durumu ("var" veya "yok") verileri ile ROC analizi gerçekleştirilir. ROC analizinden anomali tespiti için uygun eşik değerinin "3.7" olduğu belirlenmiștir. Belirlenen değer kullanılarak anomali durumları tespit edilmiștir. Şekil 3 ve Şekil 4'te sırasıyla "anomali var" ve "anomali yok" için ROC analiz grafiği sergilenmiştir. ROC Eğrisi (ROC Curve) analizi için kullanılan "Duyarlılık" ve "Özgüllük" metrikleri; Gerçek Pozitif (GP), Gerçek Negatif (GN), Yanlış Negatif (YN) ve Yanlış Pozitif (YP) oranları ile elde edilmiştir. Tanımlamalar aşağıda verilmektedir (Şekercioğlu, 2019).

$$
\begin{aligned}
& \text { Duyarlılık }=\mathrm{GP} / \mathrm{P}=\mathrm{GP} /(\mathrm{GP}+\mathrm{YN}) \\
& \text { Özgüllük }=\mathrm{GN} / \mathrm{N}=\mathrm{GN} /(\mathrm{GN}+\mathrm{YP})
\end{aligned}
$$

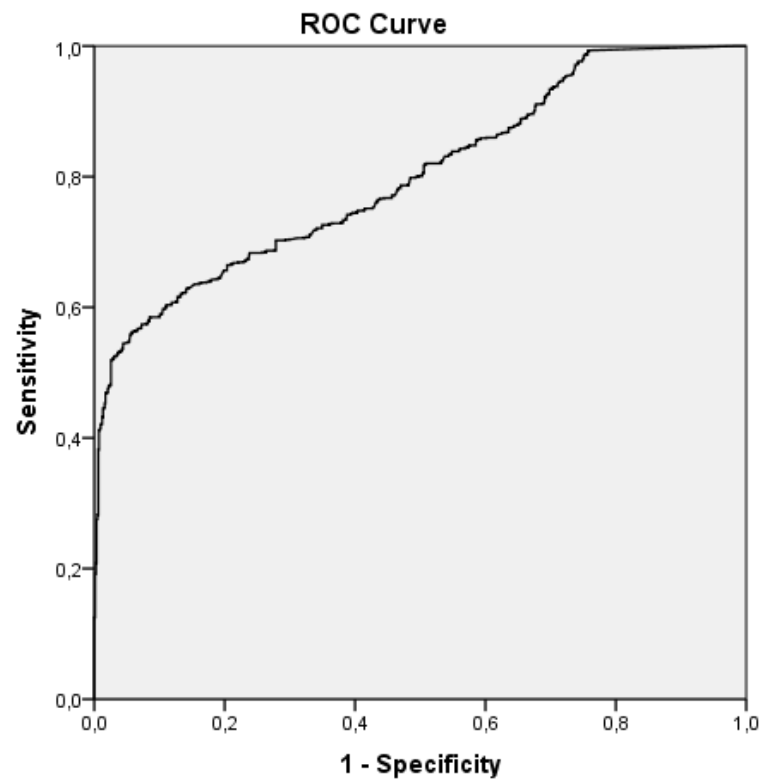

Şekil 3. "anomali var" için ROC Analiz Grafiği

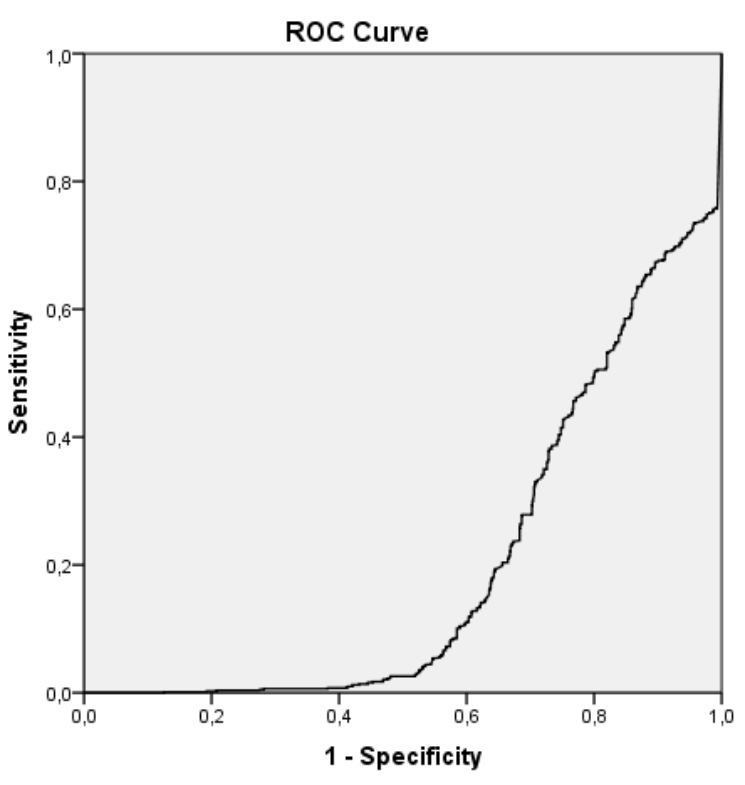

Şekil 4. "anomali yok" için ROC Analiz Grafiği

Tablo 2'de bulanık mantık tabanlı anomali tespiti sonucunda elde edilen karmaşıklı matrisi verilmektedir. Doğruluk oranı, algoritma tarafından doğru tespit edilen olayların yüzdesi olarak tanımlanır (Nikolaev ve Sapego, 2016). Yanlış negatif hata oranı, olay durumlarının yanlışlıkla olay yok olarak sinıflandırılma oranını temsil eder. Sistemin hem genel doğruluk hem de yanlış negatif hata oranı bakımından dengeli olması önemlidir. Deney sonucunda elde edilen toplam doğruluk ve yanlış negatif hata oranı Tablo 3'te verilmektedir. 
Tablo 2

Akıllı Fabrikalardaki OTA’lar için Bulanık Mantık

Tabanlı Anomali Tespiti Sonucu Elde Edilen

Karmaşıklık Matrisi

\begin{tabular}{|l|l|l|l|}
\hline \multirow{4}{*}{$\begin{array}{l}\text { Gerçek } \\
\text { Değer }\end{array}$} & Anomali: & VAR & YOK \\
\cline { 2 - 4 } & VAR & 733 & 457 \\
\cline { 2 - 4 } & YOK & 107 & 708 \\
\cline { 2 - 4 } & & & \\
\hline
\end{tabular}

Tablo 3

Akıllı Fabrikalardaki OTA'lar için Bulanık Mantık Tabanlı Anomali Tespiti Değerlendirme Metrikleri

\begin{tabular}{lcc}
\hline Yöntem & $\begin{array}{c}\text { Doğruluk } \\
\text { Oranı }\end{array}$ & $\begin{array}{c}\text { Yanlıș Negatif } \\
\text { Hata Oranı }\end{array}$ \\
\hline Bulanık Mantık & $\% 71,87$ & 0,38 \\
\hline
\end{tabular}

Ayrıca aynı veri kümesi ile Matlab ortamında Uyarlamalı A $\breve{g}$ Tabanlı Bulanık Çıkarım Sistemi (ANFIS) kullanılarak anomali tespit çalışması yapılmıştır. ANFIS, Sugeno ve yapay sinir ağını birlikte kullanan bir modeldir. Oluşturulan ANFIS modelinde giriș parametreleri; zaman, ortalama hız, işlem süresi ve yaya yoğunluğu, çıkış parametresi ise anomali olma oranıdır. Tablo 4'te verilen parametre değerleri kullanılarak ANFIS modeli oluşturulmuştur.

\section{Tablo 4}

Akıllı Fabrikalardaki OTA’lar için ANFIS Modeli Parametreleri ve Değerleri

\begin{tabular}{lc}
\hline Parametre Adı & $\begin{array}{c}\text { Parametre } \\
\text { Değeri }\end{array}$ \\
\hline Düğüm Sayısı & 193 \\
Doğrusal Parametre Sayısı & 81 \\
Doğrusal Olmayan Parametre Sayısı & 36 \\
Toplam Parametre Sayısı & 117 \\
Eğitim Veri Çifti Sayısı & 2005 \\
Bulanık Kural Sayısı & 81 \\
\hline
\end{tabular}

ANFIS modeli eğitildikten sonra 180 adet veri ile test edilmiștir. Tablo 5'de ANFIS ile anomali tespiti sonucunda elde edilen karmaşıklı matrisi verilmektedir. Deney sonucunda elde edilen toplam doğruluk, özgüllük ve duyarlılık oranı Tablo 6'da verilmektedir.

Tablo 5

Akıllı Fabrikalardaki OTA'lar için ANFIS ile Anomali Tespiti Sonucu Elde Edilen Karmașıklık Matrisi

\begin{tabular}{|l|l|l|l|}
\hline \multirow{4}{*}{$\begin{array}{l}\text { Gerçek } \\
\text { Değer }\end{array}$} & \multicolumn{3}{|c|}{ Tahmin Edilen } \\
\cline { 2 - 4 } & Anomali: & VAR & YOK \\
\cline { 2 - 4 } & VAR & 84 & 20 \\
\cline { 2 - 4 } & YOK & 47 & 29 \\
\hline
\end{tabular}

Tablo 6

Akıllı Fabrikalardaki OTA'lar için ANFIS ile Anomali Tespiti Değerlendirme Metrikleri

\begin{tabular}{lccc}
\hline Yöntem & $\begin{array}{c}\text { Doğruluk } \\
\text { Oranı }\end{array}$ & $\begin{array}{c}\text { Özgüllük } \\
\text { Oranı }\end{array}$ & $\begin{array}{c}\text { Duyarlılı } \\
\text { Oranı }\end{array}$ \\
\hline ANFIS & $\% 62,78$ & 0,59 & 0,64
\end{tabular}

\section{Tartışma}

Literatürde dış trafik ağlarında bulanık mantık tabanlı anomali tespiti yaklaşımlarında tespit edilen olayın özelliğine göre değişen \%51 ile \%100 arasında farklı anomali tespit doğruluk sonuçları bulunmuștur (El Hatri ve Boumhidi, 2018; Li ve diğ., 2018; Rossi ve di ̌̆., 2015). Ancak akıllı fabrikalar ve OTA'lar için anomali tespiti yeni bir çalışma alanıdır ve bulanık mantık tabanlı çalışmaya rastlanılmamıștır. Çalışmada literatürde trafik olay tespitinde kullanılan değişkenlere benzer ancak yaya yoğunluğu ve fabrikalar ile ilişkili işlem süresi gibi değişkenler de kullanılarak akıllı fabrikalardaki OTA'lar için bulanık mantık tabanlı anomali tespiti gerçekleştirilmiştir. Önerilen yöntem ile \%71,87 doğruluk oranı ve 0,38 yanlıs negatif hata oranı ile anomali tespiti gerçekleştirilmiştir. Fakat çalışmamızda aynı veri setine uygulamış olduğumuz ANFIS modeli bulanık mantık modelimiz kadar başarılı bir anomali tespiti ortaya koyamamıștır. Elde edilen değerler uygulama çalıșmaları için kabul edilebilir bir sonuçtur.

\section{Sonuçlar}

Akıllı fabrikalardaki OTA'lar için bulanık mantık tabanlı anomali tespiti için zaman, ortalama hız, yaya yoğunluğu ve işlem süresi verileri bulanık mantık giriş verileri olarak kullanılmış, çıkış değeri olarak anomali olma oranı ve anomali durumu bulunmuştur. Anomali olma 
oranı ile anomali durumu ("var" veya "yok") ROC analizi yapılmıştır. ROC analizi sonucunda anomali tespiti için en uygun eşik değeri "3.7" olarak belirlenmiştir. Bulanık mantık tabanlı anomali tespiti ile 2005 adet veride \%71,87 doğruluk oranı ve 0,38 yanlış negatif hata oranı elde edilmiştir. Gelecek çalışmalarda kullanılan değişken üzerine çalışma ve yöntemin geliştirilmesi hedeflenmektedir.

\section{Teşekkür}

Bu çalışma, Türkiye Bilimsel ve Teknolojik Araștırma Kurumu'nun (TUBİTAK) 116E731 nolu “Akıllı fabrikalar için otonom taşıyıcılar ve gerekli insan-makine ve makine-makine arayüzlerinin geliștirilmesi" projesi tarafından desteklenmiştir.

\section{Araştırmacıların Katkısı}

$\mathrm{Bu}$ araştırmada; Özlem ÖRNEK, bilimsel yayın araştırması, yöntem belirlenmesi, makalenin oluşturulması, uygulanması, sonuçların analiz edilmesi ve makale sonuçlarının hazırlanması; Eyyüp GÜLBANDILAR, bilimsel yayın araştırması, yöntem belirlenmesi, makalenin oluşturulması, uygulanması, sonuçların analiz edilmesi ve makale sonuçlarının hazırlanması; Ahmet YAZICI, bilimsel yayın araştırması, yöntem belirlenmesi, makalenin oluşturulması, uygulanması, sonuçların analiz edilmesi ve makale sonuçlarının hazırlanması konularında katkı sağlamışlardır.

\section{Çıkar Çatışması}

Yazarlar tarafından herhangi bir çıkar çatışması beyan edilmemiştir.

\section{Kaynaklar}

Chandola, V., Banerjee, A., \& Kumar, V. (2007). Anomaly detection: a survey. ACM computing surveys (CSUR), 41(3), 15 . doi: https://doi.org/10.1145/ $\underline{1541880.1541882}$

Dardor, M., Chlyah, M., \& Boumhidi, J. (2018, April). Incident detection in signalized urban roads based on genetic algorithm and support vector machine. Paper presented at the meeting of the International Conference on Intelligent Systems and Computer Vision (ISCV), Fez, Morocco.

Dogru, N., \& Subasi, A. (2018, February). Traffic accident detection using random forest classifier. Paper presented at the meeting of the 15th Learning and Technology Conference (L\&T), Jeddah, Saudi Arabia.
El Hatri, C., \& Boumhidi, J. (2018). Fuzzy deep learning based urban traffic incident detection. Cognitive Systems Research, 50, 206-213. doi: https://doi.org/10.1016/j.cogsys.2017.12.002

Ki, Y. K., Heo, N. W., Choi, J. W., Ahn, G. H., \& Park, K. S. (2018, January). An incident detection algorithm using artificial neural networks and traffic information. Paper presented at the meeting of the Cybernetics \& Informatics (K\&I), Lazy pod Makytou, Slovakia.

La-inchua, J., Chivapreecha, S., \& Thajchayapong, S. (2013, May). A new system for traffic incident detection using fuzzy logic and majority voting. Paper presented at the meeting of the 10th International Conference on Electrical Engineering/Electronics, Computer, Telecommunications and Information Technology, Krabi, Thailand.

Li, Y., Guo, T., Xia, R., \& Xie, W. (2018). Road traffic anomaly detection based on fuzzy theory. IEEE Access, 6, 40281-40288. doi: https://doi.org/10.1109/ACCESS.2018.2851747

Liu, Q., Lu, J., Chen, S., \& Zhao, K. (2014). Multiple Naïve bayes classifiers ensemble for traffic incident detection. Mathematical Problems in Engineering, 2014. doi: https://doi.org/10.1155/2014/383671

Mamdani, E. H., \& Assilian, S. (1975). An experiment in linguistic synthesis with a fuzzy logic controller. International journal of man-machine studies, 7(1), 113. doi: https://doi.org/10.1016/S00207373(75)80002-2

Mendel, J. M. (1995). Fuzzy logic systems for engineering: a tutorial. Proceedings of the IEEE, 83(3), 345-377. doi: https://doi.org/10.1109/ $\underline{5.364485}$

Nikolaev, A. B., \& Sapego, Y. S. (2016). IMPLEMENTATION OF INCIDENT DETECTION ALGORITHM BASED ON FUZZY LOGIC IN PTV VISSIM. International Journal of Advanced Studies, 6(4), 37-45. doi: https://doi.org/10.12731/2227930X-2016-4-37-45

Nikolaev, A. B., Sapego, Y. S., Jakubovich, A. N., Berner, L. I., \& Stroganov, V. Y. (2016). Fuzzy Algorithm for the Detection of Incidents in the Transport System. International Journal of Environmental and Science Education, 11(16), 9039-9059. Retrieved from: https://files.eric.ed.gov/fulltext/EJ1118761.pdf

Örnek, Ö, Vatan, S, Sarığlu, S ve Yazıcı, A. (2018). Trafik Ağlarında Anomali Tespiti. Eskișehir Osmangazi Üniversitesi Mühendislik ve Mimarlı Fakültesi Dergisi, $26 \quad$ (3), 132-138. doi: https://doi.org/10.31796/ogummf.440285 
Örnek, Ö., Vatan, S., Sarığlu, S., \& Yazıcı, A. (2018, October). Anomaly Detection for Autonomous Transfer Vehicles in Smart Factories. Paper presented at the meeting of the 6th International Conference on Control Engineering \& Information Technology (CEIT), İstanbul, Turkey.

Parkany, E., \& Xie, C. (2005). A complete review of incident detection algorithms \& their deployment: what works and what doesn't. Retrieved from: http://docs.trb.org/00988875.pdf

Pu, J., Wang, Y., Liu, X., \& Zhang, X. (2019). STLP-OD: Spatial and Temporal Label Propagation for Traffic Outlier Detection. IEEE Access, 7, 63036-63044. doi: https://doi.org/10.1109/ACCESS.2019.2916853

Rossi, R., Gastaldi, M., Gecchele, G. (2018). Automatic Incident Detection on Freeway Ramp Junctions. A Fuzzy Logic-Based System Using Loop Detector Data. ADVANCED CONCEPTS, METHODOLOGIES AND TECHNOLOGIES FOR TRANSPORTATION AND LOGISTICS, 572, 370-383. doi: https://doi.org/ $\underline{10.1007 / 978-3-319-57105-818}$

Rossi, R., Gastaldi, M., Gecchele, G., \& Barbaro, V. (2015). Fuzzy logic-based incident detection system using loop detectors data. Transportation Research Procedia, 10, 266-275. doi: https://doi.org/10.1016/ j.trpro.2015.09.076

Şekercioğlu, M. E. (2019). Özgüllük ve Duyarlılık Specificity and Sensitivity 1. Erişim Adresi: https://tezverianaliz.com/biyoistatistikdershanesi/ozgulluk-ve-duyarlilik-specificity-andsensitivity-1/

Tao, F., Qi, Q., Liu, A., \& Kusiak, A. (2018). Data-driven smart manufacturing. Journal of Manufacturing Systems, 48, 157-169. doi: https://doi.org/10.1016/ j.jmsy.2018.01.006

Thaika, M., Tasneeyapant, S., \& Cheamanunkul, S. (2018, July). A Fast, Scalable, Unsupervised Approach to Real-time Traffic Incident Detection. Paper presented at the meeting of the 15th International Joint Conference on Computer Science and Software Engineering (JCSSE), Nakhonpathom, Thailand.

Weil, R., Garcia-Ortiz, A., \& Wootton, J. (1998, May). Detection of traffic anomalies using fuzzy logic based techniques. Paper presented at the meeting of the IEEE International Conference on Fuzzy Systems Proceedings. IEEE World Congress on Computational Intelligence (Cat. No.98CH36228), Anchorage, AK, USA, USA.

Yujun, C., Juhua, P., Jiahong, D., Yue, W., \& Zhang, X. (2019). Spatial-temporal traffic outlier detection by coupling road level of service. IET Intelligent Transport Systems, 13(6), 1016-1022. doi: https://doi.org/10.1049/iet-its.2018.5214
Zadeh, L. A. (1988, April). Fuzzy logic. In Computer, 21, 4, 83-93. doi: https://doi.org/10.1109/2.53 